\title{
HEALTH BELIEFS ON THE BEHAVIORAL ADOPTION OF MAMMOGRAPHY SCREENING MODERATED BY KNOWLEDGE AND MARITAL STATUS: A PATH ANALYTIC MODEL
}

\author{
Soo-Foon Moey ${ }^{1}$, Norfariha Che Mohamed ${ }^{1}$ and Bee-Chiu Lim² \\ ${ }^{1}$ Department of Diagnostic Imaging and Radiotherapy, Kulliyyah of Allied Health Sciences, International \\ Islamic University Malaysia, Kuantan, Pahang, Malaysia \\ ${ }^{2}$ Clinical Research Centre, Hospital Tengku Ampuan Afzan, Kuantan, Pahang, Malaysia
}

Corresponding author: Moey Soo Foon

Email: moeysf@iium.edu.my

\begin{abstract}
Despite the effectiveness of mammography for early breast cancer detection, its' utilization among Malaysian women remains low. Health beliefs are closely related to health screening behavior. Hence, it is important that health beliefs are employed when exploring mammography screening behavior. Thus, the study utilized HBM constructs in predicting the variance in adoptive behavior of mammography. A multi-stage, stratified random sampling method was utilized to select the polyclinics in Kuantan, Pahang. Using sample size calculation at $5 \%$ type 1 error, $p<0.05$ and absolute error at 2\%, 520 Malaysian women aged 35 to 70 years were randomly selected. Sets of copyrighted, validated questionnaire were used to obtain the data. Structural equation modeling using Mplus was used to test the model. All health beliefs were found to significantly influence the behavioral adoption of mammography screening. Socio-demographic factors (married women) were found to moderate significantly the relationship between perceived susceptibility and behavioral adoption of mammography. Further, knowledge and married women were found to significantly affect selfefficacy. Additionally, perceived severity, motivator factors and perceived benefits were found to significantly influence self-efficacy and that self-efficacy significantly influences the behavioral adoption of mammography screening. However, a negative correlation was found between perceived severity and perceived barriers on the behavioral adoption of mammography. The model can be used as an interventional tool in designing promotional and educational programs to encourage women to adopt mammography screening.
\end{abstract}

Keywords: Breast cancer, Mammography, Health behavior, Health belief model, Structural equation modeling

\section{INTRODUCTION}

Breast cancer is the most common cancer amongst women in Malaysia accounting for $33.9 \%$ of all female cancer cases $^{1-3}$. As such, mammography screening practice is very important in the early detection of the disease ${ }^{4-6}$ as records indicated that about 35 to $50 \%$ of the initial cases of breast cancer were detected through mammography ${ }^{6}$. Around $6.6 \%$ were diagnosed in women less than 40 years old and $2.4 \%$ in women less than 35 years old ${ }^{7}$. This is indicative that progress into the advanced stage will be deterred if mammography is performed consistently as recommended 6 . In the average risk women aged 40 to 74 years old who partake in mammography screening every 1 to 2 years, the mortality rate is reduced by $40 \%^{8}$. Despite the potential benefits of mammography screening, the uptake amongst Malaysian women (3.6\% to $30.9 \%)$ excluding the research conducted amongst tertiary education personnel ${ }^{9}$ is still very low when compared to that in the United Kingdom (73.8\%), the United States of America (51\%), South Korea $(45.8 \%)^{10}$ and Japan $(20.3 \%)^{11}$.

Studies indicated that good breast cancer knowledge and positive health beliefs is related with mammography screening ${ }^{12-14}$. On the contrary, in Malaysia, even though $99.2 \%$ of women were aware of breast cancer as a leading disease however, less than $50 \%$ of them were aware that mammography is a good breast cancer screening tool ${ }^{14,15}$. Past studies indicated that barriers such as attitude and knowledge significantly contributed to the low uptake in breast cancer screening9,11. Additionally, the low uptake of mammography screening in Malaysia could also be because Malaysia to date does not have a population-based mammography screening program in which a target screening rate is set ${ }^{16}$ and as such, mammography screening is still opportunistic in nature. Women presented themselves at government health clinics either through an invitation to undergo mammography screening or due to them being at a high risk of breast cancer $^{16}$. Additionally, the low uptake of mammography screening in Malaysia could be due to the participants' health beliefs that they were less likely to develop breast cancer as they perceived themselves to be at a low risk of getting the disease. Further, other possible reasons are fear of breast cancer discovery ${ }^{17}$, fear that the procedure is painful ${ }^{18-20}$ and embarrassment from uncovering oneself for the procedure ${ }^{19,21}$.

Screening adoption for early detection of breast cancer is important to improve survival rates and reduce mortality from breast cancer. Early 
detection helps women to obtain treatment earliest possible when the disease is still at the curable stage and does not spread aggressively elsewhere in the body ${ }^{22}$. Early detection of breast cancer at an early stage aids in prognosis ${ }^{23}$ as early detection has been found to increase the success rate of breast cancer treatment.

Most studies on breast cancer screening adoption have utilized psychological constructs to improvise strategies or improve screening rates by developing models. Amongst them, a metaanalysis had indicated that tailored interventions derived from psychological principles have significantly improved mammography screening behavior $^{11,24}$. Above all, studies indicated that conceptualizing intentions and screening behaviors utilizing Health Belief Model (HBM) is appropriate as health behavioral theories are applied to understand theoretical mechanisms in behavioral changes and to build consensus between theoretical concepts and pathways ${ }^{25,26}$. Further, behavioral studies indicated that women's beliefs on breast cancer and mammography screening influence their behavioral adoption ${ }^{27,28}$. As such the objective of this study is to utilize HBM constructs whereby the concepts within the theory are measured in predicting the variance in adoptive behavior of mammography while controlling for moderating effects of knowledge and socio-demographic factors and mediating effects of self-efficacy using structural modeling fit analysis. The model obtained could then be used in tailoring interventional programs incorporating women's health beliefs in Kuantan, Pahang to increase their likelihood in adopting mammography screening.

\section{METHODS}

\section{Study design}

A cross-sectional study was conducted to determine the relationship of health beliefs moderated by socio-demographic factors and knowledge on behavioral adoption of mammography screening amongst women in Kuantan, Pahang.

\section{Study procedure}

Study duration

This study was carried out from 15th August 2017 to 30th September 2018 which is approximately thirteen months. Data collection was carried out from January 2018 to April 2018.

\section{Sampling and data collection}

In acquiring the desired sample size from the population, a multi-stage sampling method was used to randomly pick three sub-districts in Kuantan, Pahang. This process resulted in Sungai Karang, Beserah and Kuala Kuantan to be selected in the first stage. In the second stage, stratified random sampling was utilized to pick four largest polyclinics in the aforementioned sub-districts. As such, Klinik Kesihatan Balok from Sungai Karang and Klinik Kesihatan Beserah from Beserah were selected. As Kuala Kuantan was larger and more populated than Sungai Karang and Beserah, two polyclinics (IIUM Family Health Clinic and Klinik Kesihatan Kuantan) were randomly selected for this sub-district. Employing a simple proportion formula for sample size calculation at $5 \%$ type 1 error, $p<0.05$ and absolute error at 2\%, 130 Malaysian women from each of the aforementioned polyclinics totaling 520 participants that meets the inclusion criteria were selected randomly for the study. The inclusion criteria for the study were women aged between 35 to 70 years, living in Kuantan, Pahang and able to write or read in English and or Bahasa Malaysia. Even though the recommended age for mammography in Malaysia is 40 years and above, this study has included women aged 35 years and above. This is because approximately $2.7 \%$ of breast cancer occur in women at the age of 35 years old or younger ${ }^{29}$. At the polyclinics, women waiting for treatment or consultation were individually approached. The purpose of the study was clarified using a written information sheet. Women who verbally agreed to participate were given a set of self-administered questionnaire to complete the survey.

\section{Ethical approvals}

Ethical approvals were obtained from Medical Research and Ethics Committee (NMRR-17-213137586 (IIR)), International Islamic University Malaysia Research Ethics Committee (IREC 2017075) and the Kulliyyah Postgraduate Research Center (KAHS 173).

\section{Instrument}

The copyrighted self-constructed questionnaire was created from reviewing relevant mammography and HBM literatures. The content was validated by a committee of five health professionals consisting of a radiologist specializing in breast imaging, two professors, a research scholar in women's health and an English lecturer from the Center for Languages and PreUniversity Academic Development, IIUM. The 103 sets of questionnaire obtained from the pilot study were evaluated using exploratory factor analysis (EFA). The first section is pertaining to socio-demographics (age, race, marital status, level of education, occupation and family income) whilst the second section deals with knowledge pertaining to breast cancer screening. The third section is related to participants' health beliefs pertaining to mammography. The final section is to solicit the behavioral adoption of mammography amongst participants.

\section{Statistical analysis}

Descriptive analysis was analyzed by Statistical Package for Social Science (SPSS) version 21. Structural equation modeling (SEM) using the maximum likelihood method with robust standard errors estimator was performed to test the model 
by analyzing the relationship of knowledge, sociodemographic factors and women's beliefs towards the behavioral adoption of mammography. Confirmatory factor, path analyses for estimation of measurement and covariance equation were utilized in validating the models ${ }^{30}$. In this study, Mplus, a highly flexible software that allows users to choose various techniques for model estimation was selected to conduct the SEM techniques ${ }^{31}$. Model fit was assessed with the chi-squared statistic $\left(\chi^{2}\right)$, with $p$-value $>0.05$; the comparative fit index $(\mathrm{CFI})$, the Tucker-Lewis index (TLI), both were $>0.95$, the root mean square error of approximation (RMSEA) $<0.08$, and standardized root mean square residual (SRMR) < 0.05 , indicative of adequate model $\mathrm{fit}^{32}$. The initial path model was constructed by hypothesizing the relationships between the variables and causal direction between them. The specific hypotheses for each path are as illustrated in Figure 1.

The initial model (Figure 1), depicts the path relationships between variables; knowledge pertaining to breast cancer, socio-demographic factors (race, marital status, educational level, occupation, family income and age), health beliefs (susceptibility, severity, benefits, barriers, self-efficacy, motivator factors and cues to action) and the behavioral adoption of mammography screening. The 14 hypothesized path relationships are as in Figure 1.

Based on the conceptual framework (Figure 1), self-efficacy is assumed to mediate the relationship between socio-demographic variables and knowledge on breast cancer and behavioral adoption of mammography screening. The Mplus software was used to test the mediation effect of this relationship ${ }^{33}$. A $p$-value $<0.05$ was considered a significant indirect path. For the moderating effects of socio-demographic variables on individual health belief factor affecting the behavioral adoption of mammography screening, a biological plausible and important interaction terms were created between significant socio-demographic variables and individual health belief that influences the behavioral adoption of mammography screening ${ }^{34-}$ 36. The interaction terms were included iteratively to the path model and subsequently evaluating the level of significance of the interaction terms. A $p$-value < 0.05 in the moderation path was considered as statistically significant.

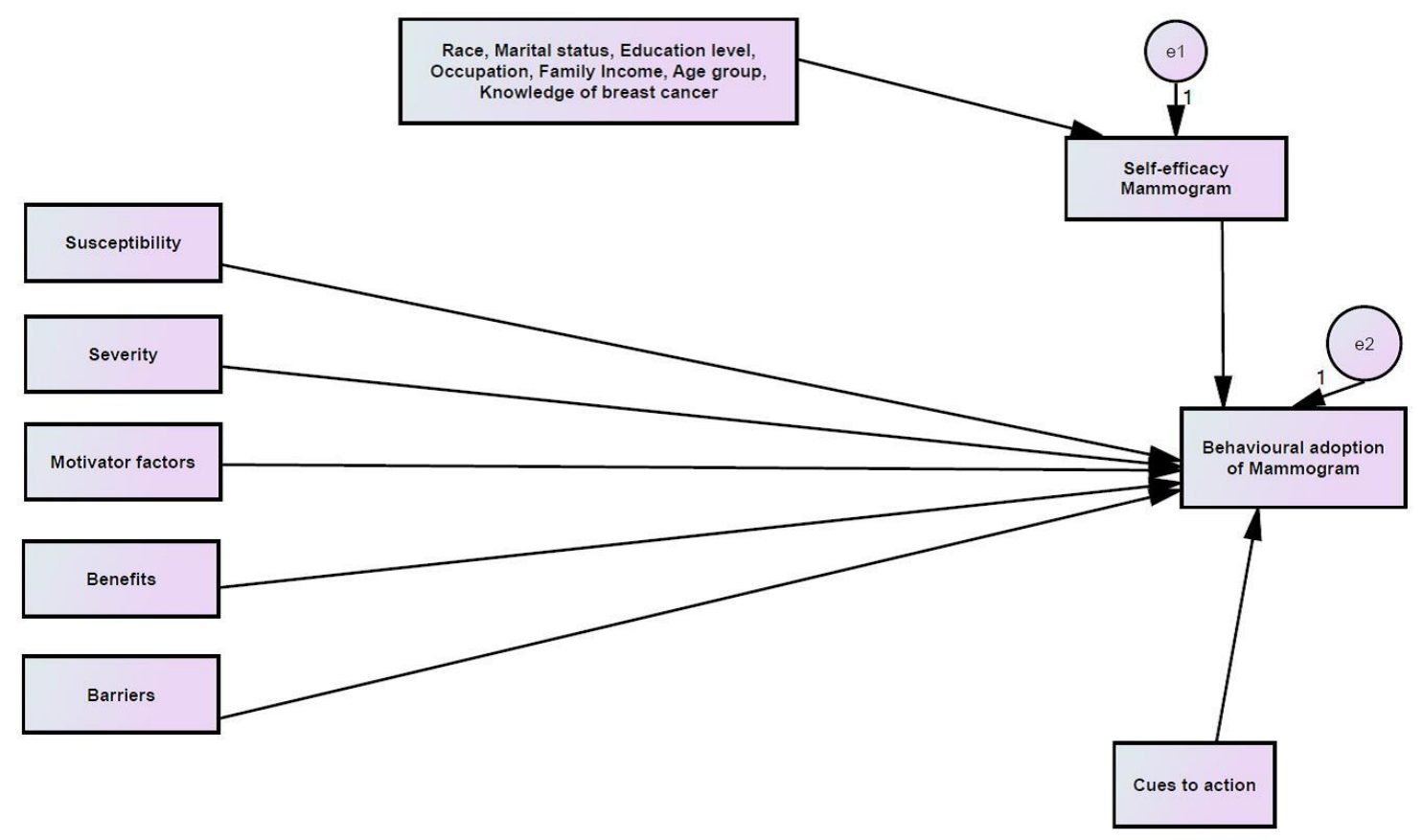

Figure 1. Initial path model (Model 1). Notes: e1 and e2 are the errors in measurement 


\section{RESULTS}

\section{Study participants}

The socio-demographic characteristics of the participants are presented in Table 1 . The mean age of the participants was 44.64 years and the majority of the participants were in the age group of 35 to 45 years. Out of 520 participants, 487

Table 1. Socio-demographic of participants.
(93.7\%) were Malays and 414 (79.6\%) were married. About $52.5 \%$ of the participants obtained tertiary education and most of them are working as government staff $(51.5 \%)$. Most of the participants (37.9\%) had a monthly family income of between RM 3000 to RM 5999.

\begin{tabular}{lcc}
\hline Variable & Frequency (n) & Percentage (\%) \\
\hline Age & 322 & \\
$35-45$ & 121 & 61.9 \\
$46-55$ & 77 & 23.3 \\
56 and above & & 14.8 \\
Race & 487 & 93.7 \\
$\quad$ Malay & 33 & 6.3 \\
$\quad$ Non-Malay & & \\
Marital status & 69 & 13.3 \\
$\quad$ Single & 414 & 79.6 \\
Married & 13 & 2.5 \\
Divorcee & 24 & 4.6 \\
Widow & & \\
Education level & 33 & 6.3 \\
No formal education to primary education & 214 & 41.2 \\
Secondary education & 273 & 52.5 \\
Tertiary education & & \\
Occupation & 99 & 19.0 \\
Private and self-employed & 268 & 51.5 \\
Government staff & 153 & 29.4 \\
Part-timer & & \\
Family income (RM) & & 11.5 \\
<1000 & 60 & 33.3 \\
1000-2999 & 173 & 37.9 \\
3000-5999 & 197 & 10.8 \\
6000-9999 & 56 & 6.5 \\
\hline 10000 & 34 &
\end{tabular}

Initial path model (Model 1)

Non-significant paths (standardized parameter estimates, B) between variables that did not explain much of the model were removed iteratively. The model was then re-tested and evaluated for fitness repeatedly. The nonsignificant paths, which were removed, were pathways linking socio-demographic variables to self-efficacy (education level, occupation, race, age and family income). Further, the paths that link individual beliefs to the behavioral adoption of mammography; cues to action to the behavioral adoption of mammography were also excluded (Model 2).
Structural model (Model 3) after addition of significant path and removal of non-significant path

Modification index (MI) suggested additional path should be added to improve the model fitness. Adequate theoretical support was carried out to investigate the path relationships suggested through MI. The path from perceived severity to self-efficacy was added into the model as suggested by MI. Further, additional paths from motivator factors and perceived benefits to selfefficacy were added. Model 3 was obtained after the addition of significant variables in the path relationships suggested by MI. The model fitness (Table 2) indicates the fit tests were within the acceptable range. Figure 2 illustrates the theoretically important and significant relationships amongst the variables hypothesized. 
Table 2. Summary of fit indices for the path models.

\begin{tabular}{lcccc}
\hline Model & \multicolumn{4}{c}{ Fit indices } \\
\cline { 2 - 5 } & RMSEA $(90 \% \mathrm{Cl}) ;$ Close-fit & CFI & TLI & SRMR \\
\hline Model 1 (Initial) & $0.160(90 \% \mathrm{Cl}: 0.143,0.179) ;<0.001$ & 0.331 & -0.377 & 0.050 \\
Model 2 & $0.135(90 \% \mathrm{Cl}: 0.108,0.164) ;<0.001$ & 0.594 & -0.129 & 0.058 \\
Model 3 (Final) & $0.012(90 \% \mathrm{Cl}: 0.000,0.068) ; 0.823$ & 0.998 & 0.993 & 0.011 \\
\hline
\end{tabular}

Notes: RMSEA = Root mean square error of approximation, Close-fit $=$ Probability of RMSEA $\leq 0.05, \mathrm{CFI}=$ Comparative Fit Index, TLI = Tucker Lewis Index, SRMR = Standardized Root Means Square Residual.

Summary of the structural model testing and models' fit indices

In summary, Model 3 (Final model) was accepted as the achieved parsimonious model after the addition of significant paths amongst the variables suggested by $\mathrm{MI}$. The $\Delta \chi_{M L R}^{2}$ was statistically significant $\chi^{2}$ as follows: $\Delta \chi_{M L R}^{2}=42.864, \mathrm{df}=9, p$ value $<0.001$. Although $\Delta \chi_{M L R}^{2}$ was significant but the majority of the fit indices suggested a good fit of the proposed structural model (Model 3) to the observed data (Figure 2).
Figure 2 depicts the results of the hypotheses tested using SEM. Out of the 17 paths tested, only 11 hypotheses were supported. All the correlation paths added in the final model were statistically significant. In order to examine the amount of variance in each latent variance that was explained by the model, the coefficient of determination $\left(R^{2}\right)$ for latent variables was also examined. The hypothesized model (Model 3 ) is used to explain the statistical amount of variance for each latent variable. The overall model explains only $10 \%$ of the variance in behavioral adoption for mammography screening and $23 \%$ of the variance in self-efficacy.

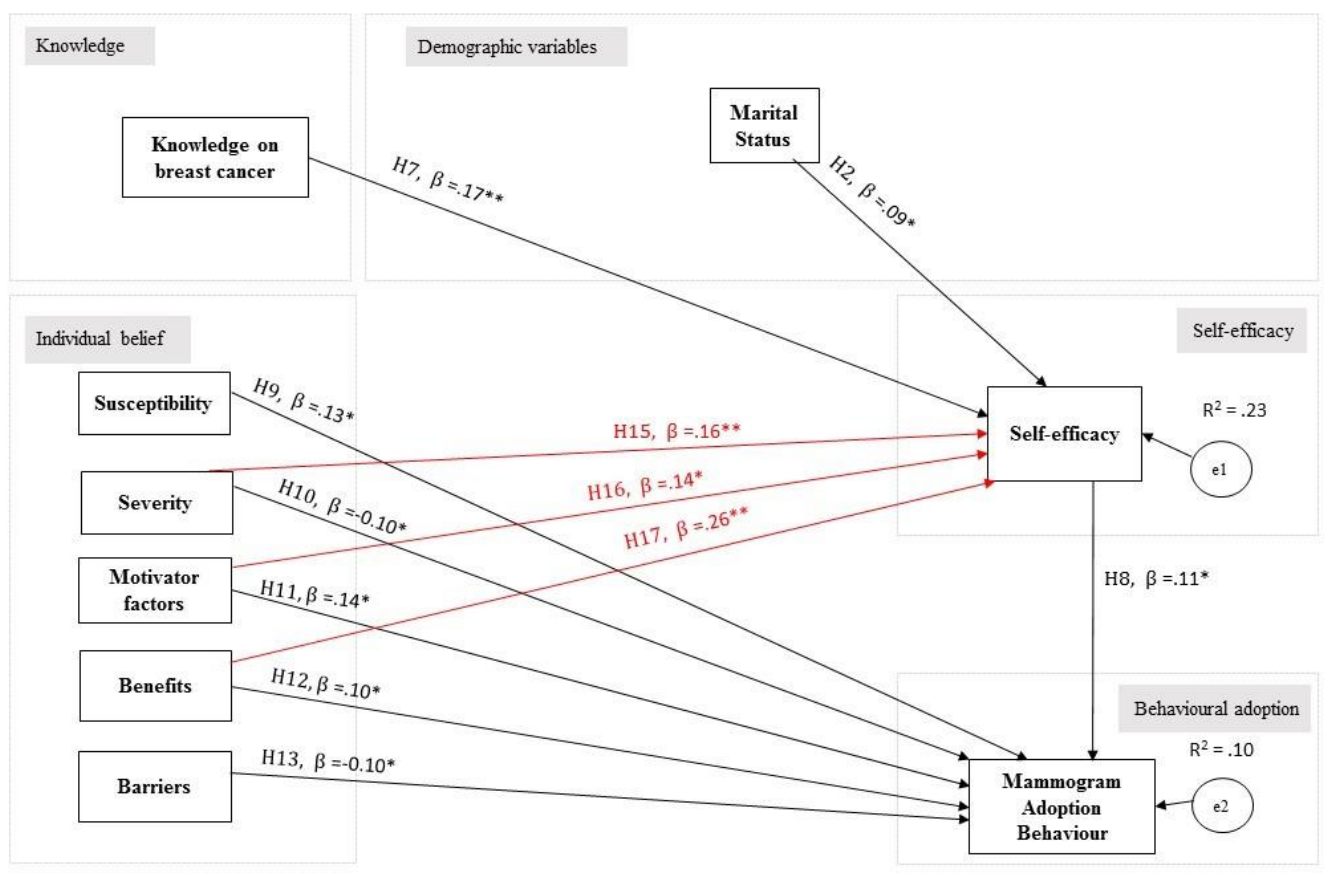

Figure 2. Model 3 (Final model) path model after additional significant paths. Notes: e1 and e2 are the error in measurement; $\mathrm{H}=$ hypothesis; ${ }^{*} p$-value $<0.05 ;{ }^{* *} p$-value $<0.001$; Line in red $=$ additional path added into the final model.

\section{Moderation on path model}

The moderation effects of knowledge and sociodemographic factors (age and marital status) on individual belief (exogenous variables) towards the behavioral adoption of mammography screening were conducted. Summary of the interaction terms (psychologically meaningful) in the final Model 3 is depicted in Table 3.
All of the hypotheses $(\mathrm{H} 9-\mathrm{H} 13)$ epitomize an insignificant moderation effect of knowledge on the relationship between individual health beliefs and behavioral adoption of mammography screening (Table 3 ) as the $p$-values are all greater than 0.05 , and therefore the hypotheses are not supported. As such, knowledge does not moderate the relationship between individual health beliefs and behavioral adoption of mammography 
screening. However, marital status (married) shows a significant moderation effect on the relationship between perceived susceptibility and behavioral adoption of mammography screening $(p$-value $=0.016)$.

Testing self-efficacy as mediator for the model Mediation analysis was conducted to evaluate whether self-efficacy changes in relation to the knowledge and socio-demographic factor (marital status) which in turn influence the behavioral adoption of mammography screening. Table 4 summarizes the results.

Self-efficacy did not mediate the effect of knowledge on the behavioral adoption of mammography screening $(p$-value $=0.057)$ and marital status (married) on the behavioral adoption of mammography screening ( $p$-value $=$ 0.142). Self-efficacy was therefore not a significant mediator for the model.

Table 3. Moderation effect of knowledge and socio-demographic (marital status) on the relationship of health beliefs and behavioral adoption.

\begin{tabular}{|c|c|c|c|c|}
\hline $\mathrm{H}$ & Relationship & $\mathrm{B}(95 \% \mathrm{Cl})$ & SE & $p$-value \\
\hline \multicolumn{5}{|c|}{ Knowledge } \\
\hline H9 & $\begin{array}{l}\text { Perceived susceptibility } \rightarrow \text { Behavioral adoption } \\
\text { of mammography screening }\end{array}$ & $0.013(-0.061,0.087)$ & 0.038 & 0.737 \\
\hline $\mathrm{H} 10$ & $\begin{array}{l}\text { Perceived severity } \rightarrow \text { Behavioral adoption of } \\
\text { mammography screening }\end{array}$ & $0.017(-0.065,0.098)$ & 0.041 & 0.686 \\
\hline $\mathrm{H} 11$ & $\begin{array}{l}\text { Motivator factors } \rightarrow \text { Behavioral adoption of } \\
\text { mammography screening }\end{array}$ & $-0.048(-0.120,0.024)$ & 0.037 & 0.192 \\
\hline $\mathrm{H} 12$ & $\begin{array}{l}\text { Perceived benefits } \rightarrow \text { Behavioral adoption of } \\
\text { mammography screening }\end{array}$ & $-0.029(-0.107,0.050)$ & 0.040 & 0.473 \\
\hline $\mathrm{H} 13$ & $\begin{array}{l}\text { Perceived barriers } \rightarrow \text { Behavioral adoption of } \\
\text { mammography screening }\end{array}$ & $-0.024(-0.111,0.062)$ & 0.044 & 0.583 \\
\hline \multicolumn{5}{|c|}{ Marital status (married) } \\
\hline H9 & $\begin{array}{l}\text { Perceived susceptibility } \rightarrow \text { Behavioral adoption } \\
\text { of mammography screening }\end{array}$ & $0.090(0.017,0.163)$ & 0.037 & *0.016 \\
\hline $\mathrm{H} 10$ & $\begin{array}{l}\text { Perceived severity } \rightarrow \text { Behavioral adoption of } \\
\text { mammography screening }\end{array}$ & $0.037(-0.040,0.114)$ & 0.039 & 0.343 \\
\hline H11 & $\begin{array}{l}\text { Motivator factors } \rightarrow \text { Behavioral adoption of } \\
\text { mammography screening }\end{array}$ & $-0.025(-0.098,0.049)$ & 0.038 & 0.506 \\
\hline $\mathrm{H} 12$ & $\begin{array}{l}\text { Perceived benefits } \rightarrow \text { Behavioral adoption of } \\
\text { mammography screening }\end{array}$ & $-0.035(-0.117,0.046)$ & 0.042 & 0.399 \\
\hline $\mathrm{H} 13$ & $\begin{array}{l}\text { Perceived barriers } \rightarrow \text { Behavioral adoption of } \\
\text { mammography screening }\end{array}$ & $0.031(-0.069,0.130)$ & 0.051 & 0.542 \\
\hline
\end{tabular}

Notes: $H$ = hypothesis, * Significant moderation path.

Table 4. Standardized direct, total indirect and total effects of self-efficacy as a mediator for the model.

\begin{tabular}{|c|c|c|c|c|}
\hline \multirow{2}{*}{ Predictor Variables } & \multirow{2}{*}{ Through } & \multicolumn{3}{|c|}{ Causal effect } \\
\hline & & Direct & Indirect & Total \\
\hline $\begin{array}{l}\text { Knowledge } \rightarrow \text { Behaviora } \\
\text { adoption of mammograp } \\
\text { screening } \\
\text { Knowledge }\end{array}$ & Self-efficacy & $\begin{array}{c}0.009 \\
p \text {-value }=0.838\end{array}$ & $\begin{array}{c}0.016 \\
p \text {-value }=0.057\end{array}$ & $\begin{array}{c}0.025 \\
p \text {-value }=0.549\end{array}$ \\
\hline $\begin{array}{l}\text { Marital status } \rightarrow \text { Behavic } \\
\text { adoption of mammograp } \\
\text { screening }\end{array}$ & & & & \\
\hline Marital status (married) & Self-efficacy & $\begin{array}{c}0.056 \\
p \text {-value }=0.189\end{array}$ & $\begin{array}{c}0.009 \\
p \text {-value }=0.142\end{array}$ & $\begin{array}{c}0.064 \\
p \text {-value }=0.127\end{array}$ \\
\hline
\end{tabular}




\section{DISCUSSION}

In this study, the pathways in the final model depicted perceived susceptibility and perceived severity of breast cancer were found to significantly influence the behavioral adoption of mammography screening. The significant relationship between the two constructs with the behavioral adoption of mammography screening reflected that perceived susceptibility is related to awareness of the risk of developing breast cancer ${ }^{37}$. This is confirmed by previous studies that lack of risk health awareness of breast cancer ${ }^{38,39}$ consequently led to low perceived susceptibility that influenced the behavioral adoption of mammography screening ${ }^{18,40}$. Further, studies also reiterated that women that have high-risk perception of breast cancer are more prone to worry and thus more likely to adopt mammography screening ${ }^{18,37,41}$. Consequently perceived severity is in tandem with perception of breast cancer as a sufficiently life-threatening disease ${ }^{41,42}$. For mammography screening to be undertaken, women's perception of the perceived threat depends on their knowledge of the disease ${ }^{43}$.

In addition, findings from this study also demonstrated that motivator factors significantly influenced the behavioral adoption of mammography screening amongst women. This finding is compatible with the findings by Mahmud \& Aljunid, ${ }^{9}$ Moodi et $\mathrm{al}^{43}$ and Dündar et $\mathrm{al}^{44}$. Motivation such as satisfied experiences encountered during mammography ${ }^{37,40}$ could be the major drive that triggers women to practice mammography screening. Furthermore, the other two HBM constructs; perceived benefits and perceived barriers, have also shown a significant influence on the behavioral adoption of mammography screening. Based on HBM, women will be more likely to adopt mammography screening if they have lower perceived barriers to screening compared to perceived benefits ${ }^{41}$. This reflects the dynamic interplay between benefits and barriers in health-seeking behavior in which perceived barriers are weighted before realizing the benefits of preventive care ${ }^{45}$. Regarding previous studies conducted amongst Malaysian women, many barriers to mammography screening have been reported that may adversely affect the adoption of mammography. These include lack of knowledge of mammography, unsure where to go for mammography, lack of time, embarrassment, fear of the test result, low income and lack of transportation $9,46,47$. As such, women must be educated or be provided with information to create awareness to reduce perceived barriers in the behavioral adoption of mammography screening ${ }^{41,48}$.

Further, perceived severity, motivator factors and perceived benefits were reflected to have a significant relationship with self-efficacy. This could be due to the importance of the fore- mentioned constructs in the theoretical framework of HBM. This relationship is justifiable as the success in the change of behavior governs how women perceived the severity of the disease and believe that the particular change will produce a beneficial outcome at an acceptable cost (perceived benefit), facilitated with high motivation. Additionally, women must be competent (self-efficacious) to overcome perceived barriers in carrying out recommended behavior ${ }^{41,49,50}$. This is because the higher the women's confidence to perform the screening in spite of various distinct barriers, the greater her self-efficacy in moving from thinking about getting screenings to achieving them ${ }^{41,51}$. As such, self-efficacy serves as the principal mechanism that initiates and guides health behavior adoption $^{45}$.

The findings of the present study also highlighted significant pathways of self-efficacy with marital status and knowledge of breast cancer. Marital status was found to significantly influence selfefficacy possibly due to married women being more concern about their health and more likely to practice mammography compared to single, divorced or widowed women ${ }^{37}$. This could also be due to the influence of parenting and family social roles that may induce health-seeking behavior amongst women ${ }^{52}$. Further, the significant association of knowledge of breast cancer and self-efficacy of women in adopting mammography screening could be due to knowledge imparts awareness ${ }^{41,53,54}$ which in turn facilitates motivation $^{55}$ in the creation of self-efficacy ${ }^{41}$ for the behavioral adoption of mammography screening ${ }^{5,43,56}$.

The overall model was found to explain $10 \%$ of the variance in the behavioral adoption of mammography screening and $23 \%$ of the variance in self-efficacy. In Social Science studies that seeks to clarify human behavior it can be expected that $\mathrm{R}$-squared values are lower than $50 \%$ as it is difficult to predict physical processes in human ${ }^{57}$. However, statistically, all the health beliefs were found to be significant predictors on the behavioral adoption of mammography screening. As such, significant conclusions can be made on how predictor value (perceived susceptibility, perceived severity, motivator factors, perceived benefits and perceived barriers) changes can affect the response value (behavioral adoption of mammography screening) for the model. Further the predictor values (perceived severity, motivator factors and perceived benefits) can be used similarly to elicit response changes for self-efficacy.

This study had several limitations. Although path analysis is to test the extent to which the hypothesized model fits the data or process behind the study phenomenon, the researchers could not conclude that the model best represents the phenomenon ${ }^{19}$. The cross-sectional design 
employed in this study limits the determination of causal inference on the relationships between variables. The answers given by the respondents may not be reflective of the actual scenario of their health beliefs and behavioral adoption of mammography as the responses given may be biased, especially when the survey is completed in the presence of researchers. Another limitation is that the model cannot be generalized to all women throughout Malaysia on the adoptive behavior of mammography screening because the data were collected exclusively from women living in Kuantan, Pahang which is different in socio-demographic makeup compared to other states in Malaysia.

\section{CONCLUSION}

In conclusion, the model reflected that for the women in Kuantan, Pahang to adopt mammography screening, knowledge and marital status (married women) influence their selfefficacy. Self-confidence was cited as the major factor in self-efficacy that encouraged women to adopt mammography screening. Further, selfefficacy is enhanced via perceived severity, motivator factors and perceived benefits. Perceived severity was found to be highly influenced by the woman's risk evaluation that goes beyond the likelihood of her getting the disease. Strong intentions aided by perceived benefits were indicated as the motivating factor that stimulated the behavioral adoption of mammography. The model can be used as an interventional tool in designing mammography promotional and educational program to encourage women in Kuantan, Pahang to adopt mammography screening for early breast cancer detection. The copyrighted, validated questionnaire can be used throughout the world for early breast cancer detection survey and possibly the development of similar models for interventional and promotional purposes to reduce breast cancer mortality.

Conflict of interest

The authors declare no potential conflict of interest.

\section{Acknowledgements}

The authors thank all participants for giving their time and cooperation in completing the questionnaire. This study is funded by the Ministry of Higher Education (MOHE), Malaysia under the Fundamental Research Grant (FRGS/1/2017/SKK05/UIAM/02/1).

\section{REFERENCES}

1. Lim GCC, Rampal S, Yahaya H. Cancer Incidence in Peninsular Malaysia, 2003-2005. The Third Report of the National Cancer Registry, Malaysia. Kuala Lumpur: National Cancer Registry, Malaysia. 2008.
2. Dahlui M, Ramli S, Bulgiba AM. Breast cancer prevention and control programs in Malaysia. Asian Pac $J$ Cancer Prev 2011;12:1-4.

3. Ministry of Health Malaysia. Malaysia National Cancer Registry Report 20122016. Putrajaya, Malaysia: National Cancer Institute.

4. Griva F, Anagnostopoulos F, Gourounti K, et al. Mammography screening within the context of the theory of planned behavior: The role of personality traits and personal factors. Int J Psychol Stud 2013;5(3):98-107.

5. Abdelaziz SH, Youssef NF, Abdel N, et al. Factors associated with mammography screening behaviors: A cross-sectional descriptive study of Egyptian women. International Journal of Medical and Health Sciences 2015;9(5):401-7.

6. Mirzaei-Alavijeh $M$, Ghorbani $P$, Jalilian F. Socio-cognitive determinants of the mammography screening uptake among Iranian women. Asian Pac J Cancer Prev 2018;19(5):1351-5.

7. Assi HA, Khoury KE, Dbouk $\mathrm{H}$, et al. Epidemiology and prognosis of breast cancer in young women. J Thorac Dis. 2013;5 Suppl 1(Suppl 1):S2-S8.

8. Seely JM, Alhassan T. Screening for breast cancer in 2018-What should we be doing today? Curr Oncol 2018;25(S1):S115-24.

9. Mahmud A, Aljunid SM. The uptake of mammogram screening in Malaysia and its associated factors: A systematic review. Med J Malaysia 2018b;73(4):202-11.

10. Foundation for Promotion of Cancer Research. International comparisons of cancer mortality and cancer screening rates. Cancer statistics in Japan 2009, 2009.

11. Hirai K, Harada K, Seki A, et al. Structural equation modeling for implementation intentions, cancer worry, and stages of mammography adoption.

Psycho-Oncology 2013;22:2339-46.

12. Yip CH, Smith RA, Anderson BO, et al. Guideline Implementation for breast healthcare in low- and middle-income countries. Cancer 2008;113:2244-56. 
13. Anderson BO, Cazap E, Saghir NSE, et al. Optimization of breast cancer management in low- resource and middle- resource countries: executive summary of the Breast Health Global Initiative consensus, 2010. Lancet Oncol 2011;12:387-98.

14. Yusof A, Chia YC, Hasni YM. Awareness and prevalence of mammography screening and its predictors--a cross sectional study in a primary care clinic in Malaysia. Asian Pac $J$ Cancer Prev 2014;15(19):8095-9.

15. Kanaga K, Nithiya J, Shatirah N. Awareness of breast cancer and screening procedures among Malaysian women. Asian Pac J Cancer Prev 2011;12:1965-7.

16. Mahmud A, Aljunid SM. Availability and accessibility of subsidized mammogram screening program in peninsular Malaysia: A preliminary study using travel impedance approach. PLoS One 2018a;13:e0191764.

17. Patel K, Kanu M, Liu J, et al. Factors influencing breast cancer screening in low-income African Americans in Tennessee. J Community Health 2014;39(5):943-950.

18. Allahverdipour $\mathrm{H}$, Asghari-Jafarabadi M, Emami A. Breast cancer risk perception, benefits of and barriers to mammography adherence among a group of Iranian women. Women Health 2011;51:204-19.

19. Mamdouh H, El-Mansy H, Kharboush I, et al. Barriers to breast cancer screening among a sample of Egyptian females. J Fam Community Med 2014;21(2):119-24.

20. Taymoori P, Berry T, Roshani D. Differences in Health Beliefs Across Stage of Adoption of Mammography in Iranian Women. Cancer Nurs 2014;37(3): 208-217.

21. Alexandraki I, Mooradian AD. Barriers Related to Mammography Use for Breast Cancer Screening Among Minority Women. J Natl Med Assoc 2010;102(3): 206-218.

22. Valastyan S, Weinberg R. Tumor Metastasis: Molecular Insights and Evolving Paradigms. Cell 2011;147(2): 275-292.
23. Sun Y, Zhao Z, Yang Z, et al. Risk Factors and Preventions of Breast Cancer. Int J Biol Sci 2017;13(11): 1387-1397.

24. Sohl SJ, Moyer A. Tailored interventions to promote mammography screening: A metaanalytic review. Prev Med 2007;45(4):252-61.

25. Institute of Medicine. Speaking of Health: Assessing Health Communication Strategies for Diverse Populations. Washington, DC: The National Academies Press 2002:28-75.

26. Murphy CC, Vernon SW, Diamond PM, et al. Competitive testing of health behavior theories: how do benefits, barriers, subjective norm, and intention influence mammography behavior? Ann Behav Med 2014;47(1):120-9.

27. Spencer L, Pagell F, Adams T. Applying the transtheoretical model to cancer screening behavior. Am J Health Behav 2005;29(1):36-56.

28. Russell KM, Monahan P, Wagle A, et al. Differences in health and cultural beliefs by stage of mammography screening adoption in African American women. Cancer 2007;109(2 Suppl):386-95.

29. Juanita J, Jittanoon $P$, Boonyasopun U. BSE Practice and BSE Self-Efficacy among Nursing Students in Aceh, Indonesia. Nurse Media J Nurs 2013;3(1):557-568.

30. Chukmaitov A, Wan TTH, Menachemi $\mathrm{N}$, et al. Breast cancer knowledge and attitudes toward mammography as predictors of breast cancer preventive behavior in Kazakh, Korean, and Russian women in Kazakhstan. Int J Public Health 2008;53:123-30.

31. Barbeau K, Boileau K, Sarr F, et al. Path analysis in Mplus: A tutorial using a conceptual model of psychological and behavioral antecedents of bulimic symptoms in young adults. Quant Meth Psych 2019;15(1):38-53.

32. Hu L-t, Bentler PM. Cutoff criteria for fit indexes in covariance structure analysis: Conventional criteria versus new alternatives. Structural Equation Modeling 1999;6(1):1-55. 
33. Wang J, Wang X. Structural equation modeling: applications using Mplus. 2nd ed. United Kingdom: John Wiley \& Sons Ltd 2012.

34. Fedak KM, Bernal A, Capshaw ZA et al. Applying the Bradford Hill criteria in the 21st century: how data integration has changed causal inference in molecular epidemiology. Emerg Themes Epidemiol 2015;12(14).

35. Hayes AF. Introduction to Mediation, Moderation, and Conditional Process Analysis: A Regression-Based Approach, Guilford Press. New York, NY. 2013.

36. Perez LG, Elder JP, Haughton J, et al. Socio-demographic Moderators of Associations between Psychological Factors and Latinas' Breast Cancer Screening Behaviors. J Immigr Minor Health 2018;20(4):823-830.

37. Ramli HA, Moey SF, Mutalib AMA. The relationship of health beliefs on the stage of mammography behavior adoption amongst women in Kuantan, Pahang. Asian Pac J Cancer Prev 2019;20(6):1913-20.

38. Wu TY, Hsieh HF, West BT. Demographics and perceptions of barriers toward breast cancer screening among Asian-American women. Women Health 2008;48(3):261-81.

39. Donnelly TT, Al-Khater AH, Al-Bader SB, et al. Beliefs and attitudes about breast cancer and screening practices among Arab women living in Qatar: A cross-sectional study. BMC Womens Health 2013;13:49.

40. Gierisch JM, Earp JA, Brewer NT, et al. Longitudinal predictors of nonadherence to maintenance of mammography. Cancer Epidemiol Biomarkers Prev 2010;19(4):1103-11.

41. Glanz K, Rimer BK, Viswanath K. Health Behavior and Health Education: Theory, Research, and Practice. 4th ed. United Kingdom: John Wiley \& Sons 2008.

42. Shirzadi S, Allahverdipour H, Sharma $M$, et al. Perceived barriers to mammography adoption among women in Iran: A qualitative study. Korean J Fam Med 2020;41:20-7.
43. Moodi M, Rezaeian M, Mostafavi F, et al. Determinants of mammography screening behavior in Iranian women: A population-based study. J Res Med Sci 2012;17(8):750-9.

44. Dündar PE, Özmen D, Öztürk B, et al. The knowledge and attitudes of breast self-examination and mammography in a group of women in a rural area in western Turkey. BMC Cancer 2006;6(43):1-9.

45. Ahmadian M, Samah AA. Application of health behavior theories to breast cancer screening among Asian women. Asian Pac J Cancer Prev 2013;14(7):4005-13.

46. Rosmawati NHN. The usage and knowledge of mammogram among women in sub-urban area in Terengganu, Malaysia. Asian Pac J Cancer Prev 2010;11:767-71.

47. Al-Naggar RA, Bobryshev YV. Practice and barriers of mammography among Malaysian women in the general population. Asian Pac J Cancer Prev 2012;13:3595-3600.

48. Swapana M, Padmavathy C. A critical review on breast cancer literature: Screening, awareness and preventive measures. Mediterr $J$ Soc Sci 2015;6(4):256-63.

49. Luszczynska A, Schwarzer R. Planning and self-efficacy in the adoption and maintenance of breast selfexamination: A longitudinal study on self-regulatory cognitions. Psychol Health 2003;18(1):93-108.

50. Roh S, Burnette CE, Lee YS, et al. Breast cancer literacy and health beliefs related to breast cancer screening among American Indian women. Soc Work Health Care 2018;57:465-82.

51. Secginli S. Mammography selfefficacy scale and breast cancer fear scale: Psychometric testing of the Turkish versions. Cancer Nurs 2012;35(5):365-73.

52. Bonsu AB, Ncama BP. Recognizing and appraising symptoms of breast cancer as a reason for delayed presentation in Ghanaian women: A qualitative study. PLoS One 2019;14(1):1-21.

53. Al-Dubai SAR, Qureshi AM, Saif-Ali R, et al. Awareness and knowledge of breast cancer and mammography 
among a group of Malaysian women in Shah Alam. Asian Pac J Cancer Prev 2011;12:2531-8.

54. Sambanje MN, Mafuvadze B. Breast cancer knowledge and awareness among university students in Angola. Pan Afr Med J 2012;11:70.

55. Noreen M, Murad S, Furqan M, et al. Knowledge and awareness about breast cancer and its early symptoms among medical and non-medical students of Southern Punjab, Pakistan. Asian Pac J Cancer Prev 2015;16(3):979-84.
56. Diab S, Wahdan I, Gawwad EA, et al. Mammography screening utilization behavior among Egyptian female employees in Alexandria. Journal of High Institute of Public Health 2018;48(2):114-24.

57. Frost J. How To Interpret R-squared in Regression Analysis. Available at: https://statisticsbyjim.com/regressi on/interpret-r-squared-regression/. (Accessed December 7, 2019). 